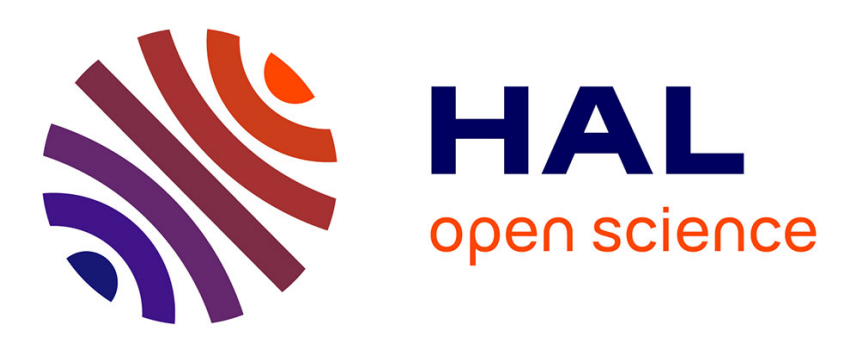

\title{
Novel millimeter-wave gas sensor using dielectric resonator with sensitive layer on $\mathrm{TiO} 2$
}

Hamida Hallil, Philippe Menini, Hervé Aubert

\section{To cite this version:}

Hamida Hallil, Philippe Menini, Hervé Aubert. Novel millimeter-wave gas sensor using dielectric resonator with sensitive layer on TiO2. IEEE Sensors 2009, Oct 2009, Christchurch, New Zealand. pp.226 - 228, 10.1109/ICSENS.2009.5398185 . hal-00672681

\section{HAL Id: hal-00672681 \\ https://hal.science/hal-00672681}

Submitted on 20 Jun 2019

HAL is a multi-disciplinary open access archive for the deposit and dissemination of scientific research documents, whether they are published or not. The documents may come from teaching and research institutions in France or abroad, or from public or private research centers.
L'archive ouverte pluridisciplinaire HAL, est destinée au dépôt et à la diffusion de documents scientifiques de niveau recherche, publiés ou non, émanant des établissements d'enseignement et de recherche français ou étrangers, des laboratoires publics ou privés. 


\section{Novel millimeter-wave gas sensor using dielectric resonator with sensitive layer on $\mathrm{TiO}_{2}$}

\author{
H. Halli1 ${ }^{1,2}$, P. Ménini ${ }^{1,2}$, and H. Aubert ${ }^{1,2}$ \\ ${ }^{1}$ CNRS; LAAS; 7, avenue du Colonel Roche, F-31077 \\ ${ }^{2}$ University of Toulouse; UPS, INP, LAAS; F-31077 \\ Toulouse, FRANCE \\ hhalli1@1aas.fr
}

\begin{abstract}
A new generation of gas sensors that operates at millimeter-wave frequency range is presented. The sensor uses a dielectric resonator operating with whispering-gallery modes. Here the dielectric resonator is covered by $\mathrm{TiO}_{2}$ thin film as sensitive layer. A gas or humidity adsorption makes the $\mathrm{TiO}_{2}$ dielectric permittivity changing and such changing modifies the resonant frequencies of high-Q whispering-gallery modes within the dielectric resonator. From the measurement of these resonant frequencies the humidity concentration can be derived. Here, the proof of concept is demonstrated through full wave electromagnetic simulations. This humidity (gas) sensor can be remotely interrogated and has great potential for wireless sensing network applications.
\end{abstract}

\section{INTRODUCTION}

The explosion of the market telecommunications allowed the emergence of new wireless gas sensors operating at microwave and millimeter frequencies [1]. The existing semiconductors sensors generally composed by sensitive layer such as $\mathrm{TiO}_{2}, \mathrm{SnO}_{2}, \mathrm{WO}_{3}$, etc, are well-known due to their high sensitivity for gases and low cost production. In presence of gas, the electrical properties of these materials change and lead a modification in their conductivity. This kind of sensor operates at high temperatures which increases their power consumption. Their operating mode at low frequencies requires techniques of modulation to insure the wireless connection and consequently, the system becomes cumbersome and requires batteries and power supplies [2, 3].

In microwave domain, the dielectric resonator is a good candidate for gas detection due to its large surface area and sensitivity for external environments. These main issues raised potential to be used a very high efficient structure in this context [4]. The excitations of the dielectric resonator (DR) with Whispering-Gallery Modes (WGM) have many advantages over the conventional excitation Transverse Electrical (TE) or Transverse Magnetic (TM) modes. DR operating with WGM has relatively large dimensions and a higher quality factor Q. Moreover, it can be excited differently, and can run in the azimuthally direction, that gives it potentialities to detect gas perturbation in every directions. In this study, we design and simulate a DR structure coupled with microwave waveguides in coplanar technology. This coupling allows very high selective performances [5].

The $\mathrm{TiO}_{2}$ is used here as the sensitive layer, as it is very sensitive to gas adsorption. Moreover, this metal oxide presents permittivity relaxation at very high frequencies due to the presence of gases, which could be exploited to build a new detector in the microwave and millimeter-wave regimes $[6,7]$.

\section{DESIGN OF THE GAS DETECTOR BASED ON WHISPERING- GALLERY MODES}

In this study, we design and simulate a dielectric resonator structure that incorporates a $\mathrm{TiO}_{2}$ sensitive layer coupled with microwave waveguides in coplanar topology for high performance in term of gas sensitivity.

The proposed resonator-based sensor is shown in Fig.1 (a). It consists of two main blocks: the coplanar waveguides (CPW) (see fig.1 (b)) used for electromagnetic propagation and the DR with $\mathrm{TiO}_{2}$ layer used for gas detection (see fig.1 (c)). These two parallel CPW are deposited over a $\mathrm{SiO}_{2} / \mathrm{SiN}_{\mathrm{x}}$ membrane with $\mathrm{Ti} / \mathrm{Au}$ metallization with $\varepsilon_{\mathrm{r}}=1.09, \mathrm{~L}=13 \mathrm{~mm}$, $\mathrm{W}=300 \mu \mathrm{m}, \mathrm{S}=30 \mu \mathrm{m}$ and $\mathrm{H}_{\text {metal }}=1 \mu \mathrm{m}$. The CPW impedance characteristic is $75 \Omega$. We choose the DR material composition with BaSmTiOxide from TEMEX CERAMICS because it presents high Q-factor, and high temperature stability [8]. The DR characteristics are the following: dielectric constant equals to 78 , typical Q-factor around 1600 at $5 \mathrm{GHz}$, diameter $\mathrm{D}_{\mathrm{DR}}$ $=6.5 \mathrm{~mm}$ and thickness $\mathrm{H}_{\mathrm{DR}}=350 \mu \mathrm{m}$. The DR is mounted above the coplanar lines by using $\mathrm{Al}_{2} \mathrm{O}_{3}$ dielectric spacer $\left(\varepsilon_{\mathrm{r}}=9.8\right)$ [8] with diameter $\mathrm{D}_{\text {spacer }}=2.7 \mathrm{~mm}$ and height $\mathrm{H}_{\text {spacer }}=260 \mu \mathrm{m}$. From full wave electromagnetic simulations, the dimensions of the spacer leads to the desired electromagnetic coupling between the WGM modes in the DR and the fundamental quasi-TEM mode in the two CPW $\left(\mathrm{H}_{\text {spacer }}=230 \mu \mathrm{m}\right.$ and $\left.\mathrm{H}_{\text {spacer }}=280 \mu \mathrm{m}\right)$. 
We choose $\mathrm{TiO}_{2}$ material as film layer with relative dielectric permittivity of 80 [9] and with thickness of $\mathrm{H}_{\mathrm{TiO} 2}=10 \mu \mathrm{m}$. The whole sensor is laid out on a high resistive silicon substrate with $\varepsilon_{\mathrm{r}}=11.6$ and thickness of $\mathrm{H}_{\mathrm{Si}}=350 \mu \mathrm{m}$. In order to work with the band-pass filter between port 1 and port 3 , the ports 2 and 4 are shunted by standard $50 \Omega$-impedances.

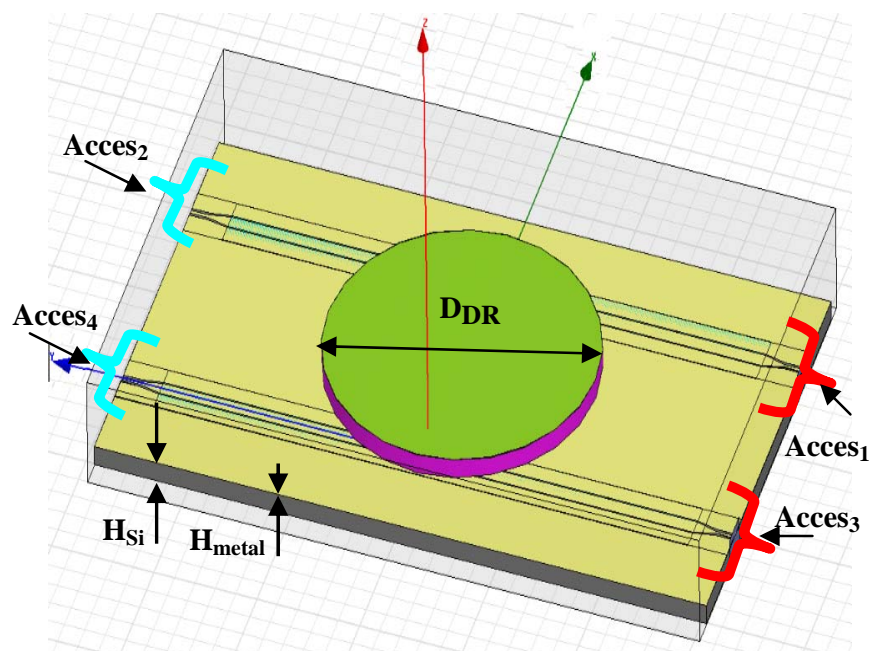

Figure 1. (a) Sensor schematic concept: Cell used to measure the gas concentration.

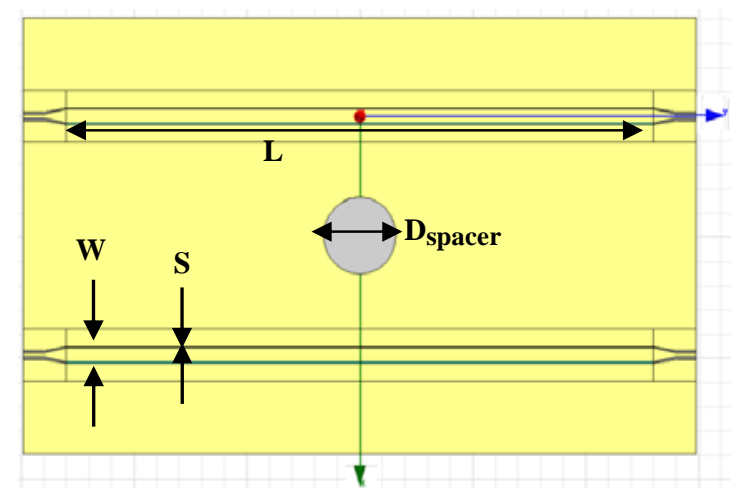

Figure 1. (b) Two coplanar lines micro-machined;

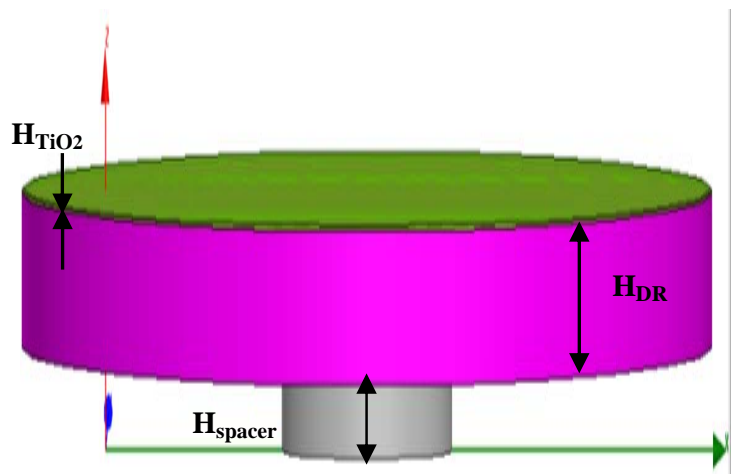

Figure 1. (c) Dielectric resonator with sensitive layer $\mathrm{TiO}_{2}$ and spacer.

\section{DESCRIPTION OF THE DETECTION PRINCIPLE AND SIMULATION RESULTS}

Figure 2 shows the functionality of the structure in large operating millimeter-wave frequency band. The DR operating with $\mathrm{WGH}_{6.2 .0}$ shows a resonant frequency at $33.24 \mathrm{GHz}$ with a quality factor of 370 . We chose this frequency because there is low insertion losses $(-5.70 \mathrm{~dB})$ and provides a good coupling between CPW quasi-TEM mode and the WGM in the DR. The magnitude of this coupling is depicted versus frequency in Figure 2. There is a significant coupling magnetic field between the coplanar waveguides and the dielectric resonator.

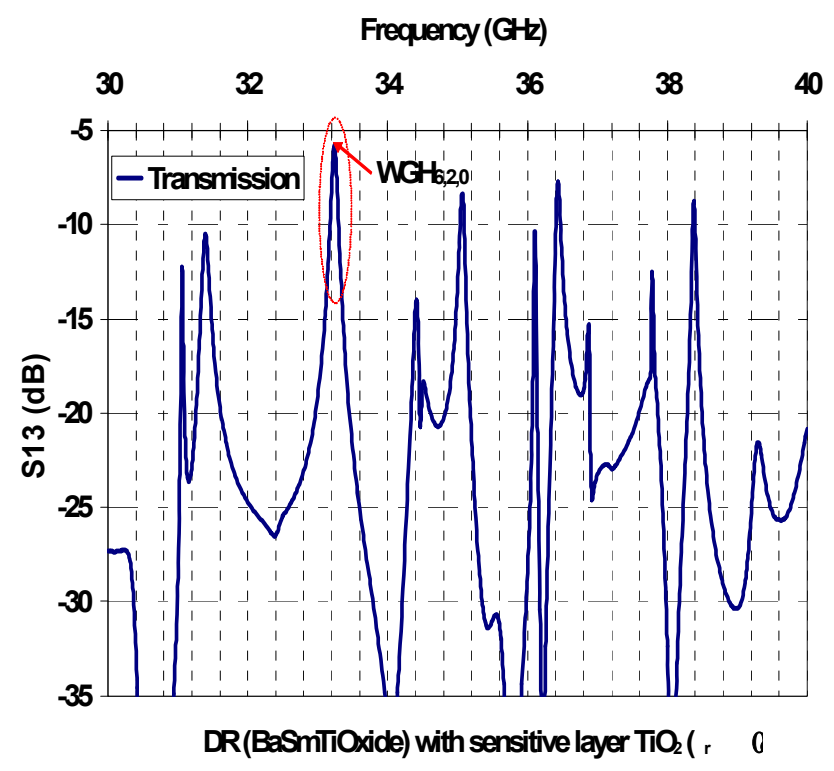

Figure 2. Simulation results of the structure coupling coefficient (magnitude of $\mathrm{S}_{13}$ ) using full-wave electromagnetic simulation $\left(\mathrm{HFSS}^{\mathrm{TM}}\right)$.

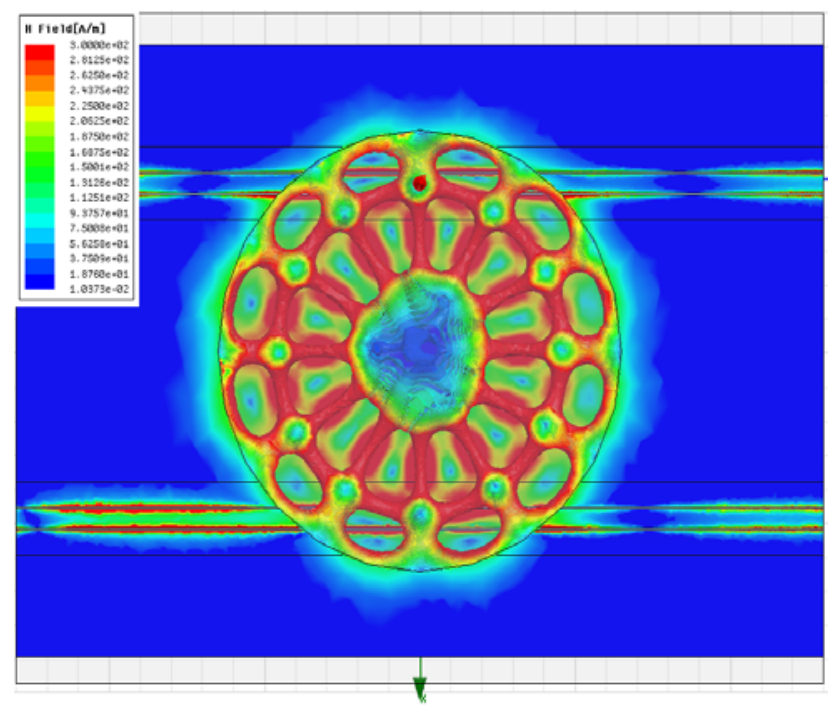

Figure 3. Amplitude of the $\mathrm{WGH}_{6,2.0}$ mode magnetic field at resonant frequency $33.24 \mathrm{GHz}$. 
The magnitude of the $\mathrm{WGH}_{6.2 .0}$ magnetic field at this resonant frequency (33.24GHZ) is depicted in Figure 3 and shows a characteristic distribution of Whispering-Gallery Modes.

\section{INFLUENCE OF HUMIDITY ON THE SENSOR}

Thanks to results reported in literature, the permittivity of $\mathrm{TiO}_{2}$ material depends on the humidity $\left(\mathrm{H}_{2} \mathrm{O}\right)$ [10]. For example, in presence of $\mathrm{H}_{2} \mathrm{O}$ the dielectric permittivity of $\mathrm{TiO}_{2}$ tends to decrease by $18 \%$. To analyze the impact of this change in permittivity on the resonant frequency of the WGM, we perform full-wave electromagnetic simulations based on the Finite-Element Method (HFSS ${ }^{\mathrm{TM}}$ ) [11] by adopting relative dielectric permittivity taken between 70 and 90 . This variation is found to be $10 \%$ on the permittivity of $\mathrm{TiO}_{2}$. As shown in Figure 4, the resulting resonant frequency of WGMbased resonator takes values that can reach almost $7 \%$ on the resonant frequency of the $\mathrm{WGH}_{6,2.0}$ mode.

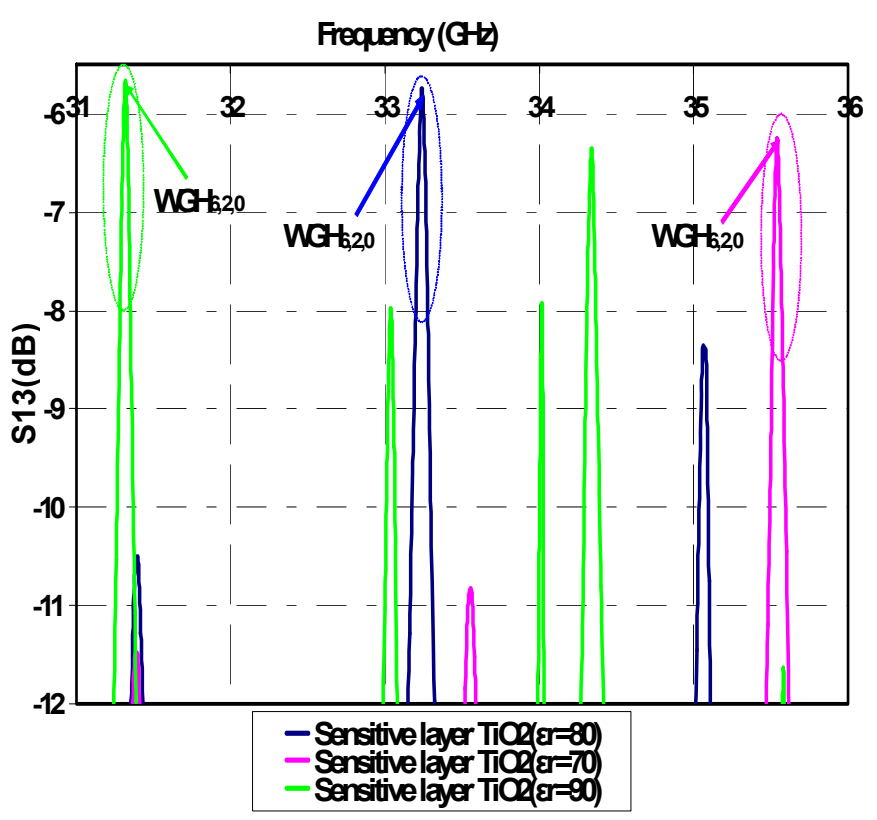

Figure 4. Transmission coefficient at the $\mathrm{WGH}_{6.2 .0}$ mode in presence of $\mathrm{H}_{2} \mathrm{O}$.

The absorption of another gaseous molecule can generate the same effects, thus we can conjecture that we can design an excellent sensor of gas in the broad sense. Experimental validations are under way.

Moreover we have recently shown an example of detection of ethylene gas with a sensitive layer $\mathrm{SnO}_{2}$ and keeping the same design of the presented detector [12].

\section{CONCLUSION}

The potentialities of a novel gas sensor using WhisperingGallery Modes have been proved thanks to full wave electromagnetic simulations. The high sensitivity in the frequency response of the proposed gas (humidity) detector device based on high-Q Whispering-Gallery Modes is very interesting for developing unique gas detection with ease of integration of the radio-frequency function. These Gas sensors are now under fabrication and experimental validation will be available soon.

\section{REFERENCES}

[1] J. Jouhannaud, J. Rossignol, D. Stuerga, "Metal oxide-based gas sensor and microwave broad-band measurements: an innovative approach to gas sensing”, Journal of Physics'”76, Conference Series, 2007.

[2] D.D. Lee, D.S. Lee, “ Environmental gas sensors”, IEEE Sensors J., Vol. 1, no. 3, 2001, pp.214-224.

[3] The Newsteo website [Online] Available: LOG242 http://www.newsteo.com/fr/f_log242.php.

[4] Darko Kajfez and Pierre Guillon. " Dielectric Resonators". Norwood,MA 02062 : Artech house,1986.

[5] D. Cros, P. Guillon, "Whispering Gallery Dielectric Resonator Modes for W-Band Devices", IEEE Trans. Microwave Theory Tech, 1990, vol.38, no. 11 pp. 1667-1674.

[6] G. Boudouris, "Phénomènes de relaxation diélectrique présentés par les gaz dans le domaine des microondes", J. Rivista del Nuovo Cimento, 1969, vol. 01, no. 1 pp. 1-56.

[7] E. Refus et.al, " Dielectric Relaxation studies of Biological Tissues in the Microwave Frequency Range ", Asian Pacific Microwaves Conference, December. 4-7,2005, Volume: 1, On page(s): 4 pp .

[8] TEMEX CERAMICS website [Online] Available, Dielectric resonators http://www.temex-ceramics.com.

[9] R. Hoffmann, "Hand book of microwave integrated circuits", Norwood, MA: Artech House, 1987, pp.527.

[10] V.A. Skryshevsky et.al, "Electrical characterization of gas sensing devices based on porous $\mathrm{TiO}_{2}$ ", Phys .stat. sol., (a) 197, 2003, no.2, pp.534-538.

[11] HFSS $^{\mathrm{TM}}$ : The Ansoft High Frequency Structure Simulator, 3D Fullwave Electromagnetic Field Simulation. HFSS v11.1, 2008.

[12] H. Hallil, P. Ménini, H. Aubert, “ Novel microwave gas sensor using dielectric resonator with $\mathrm{SnO}_{2}$ Sensitive Layer", to be presented at Eurosensors XXIII conference, Switzerland, September 6-9, 2009. 